\title{
Effect of Wood Shaving to Improve the Properties of Particleboard Made from Sorghum Bagasse
}

\author{
Apri Heri Iswanto ${ }^{1}$, Irawati Azhar ${ }^{1}$, Arida Susilowati ${ }^{1}$, Supriyanto ${ }^{2}$, Andrianta Ginting ${ }^{1}$ \\ ${ }^{1}$ Faculty of Forestry, University of Sumatra Utara, Medan, Indonesia \\ ${ }^{2}$ SEAMEO-BIOTROP, Bogor, Indonesia
}

Email address:

apri@usu.ac.id (A. H. Iswanto), irfari@yahoo.co.id (I. Azhar), arida_iswanto@yahoo.co.id (A. Susilowati), supriyanto@biotrop.org (Supriyanto)

\section{To cite this article:}

Apri Heri Iswanto, Irawati Azhar, Arida Susilowati, Supriyanto, Andrianta Ginting. Effect of Wood Shaving to Improve the Properties of Particleboard Made from Sorghum Bagasse. International Journal of Materials Science and Applications. Vol. 5, No. 2, 2016 , pp. 113-118. doi: $10.11648 /$ j.ijmsa.20160502.23

Received: April 27, 2016; Accepted: May 7, 2016; Published: May 14, 2016

\begin{abstract}
The objective of this research was to evaluate the effect of wood shaving added to improve the mechanical properties of particleboard. Wood types were using in this research included of Meranti, Cempedak, Mahagony, and Durian wood. Ratio of Sorghum bagasse and wood shaving was 50/50 (\%w/w). Amount of $10 \%$ urea formaldehyde (UF) resin used for binding in the manufacturing process. Furthermore, hot pressing of mat at $130^{\circ} \mathrm{C}$ temperature for 10 minute and $30 \mathrm{~kg} \mathrm{~cm}^{-2}$ pressure. The final step was conditioning process for 7 days at room temperature before testing of sample. The results showed that the thickness swelling (TS) parameter did not met of JIS A 5908 (2003). Overall the present of wood shaving resulted in decreasing of TS value. Combination of Cempedak and Mahagony wood resulted of the lower TS value compared with control and other treatment. For bending properties, combination of sorghum bagasse and Cempedak wood shaving resulted the best of bending properties. However for the MOE parameter had not met JIS A 5908 (2003). The internal bond (IB) parameter showed that the utilization of wood shaving to produce of particleboard caused of increasing the IB value. The IB value was resulting from this research had met of JIS A 5908 (2003).
\end{abstract}

Keywords: Wood Shaving, Sorghum Bagasse, UF Resin, Particleboard

\section{Introduction}

Sorghum bagasse as an agriculture material waste had bulky characteristic, bark part of Sorghum bagasse is smooth relatively has hydrophobic which can disrupt the adhesive penetration into particles and weaken the particle bonding. This material will result the low properties of particleboard when using as raw material in the manufacturing of board. In the previous research, Iswanto et al. (2014) reported that Sorghum bagasse particleboard with Urea Formaldehyde (UF) resin for binding resulted low dimensional stability and mechanical properties. Many researchers had conducted of research to improve the particleboard quality. Iswanto et al (2012) reported the effect of wood particle and Jatropha fruit hulls combination to improve of strength properties of board. While for Subiyanto et al (2008), Norvydas and Minelga (2006), and Iswanto, (2014) using veneer or thin plywood for surface laminates.

The present of wood in non wood particleboard had increased of board properties. Wood shaving added in manufacture of Jatropha fruit hulls particleboard resulted of improvement the strength properties (Iswanto et al. 2014). Furthermore, Bektas et al. (2005) reported that combination wood chip, fiber modification from agriculture plant and water repellent materials were promise to produce the better properties of particleboard. Russell et al. (1999) stated high stressed lumber was used as surface laminates and low stress lumber for core laminates resulted of high strength lumber. According to that described, the research to improve of inferior properties had been conducted. The objective of this research was to evaluate the physical and mechanical properties of particleboard made from combination of sorghum bagasse and wood shaving. 


\section{Materials and Methods}

\subsection{Materials}

Sorghum bagasse was collected from SEAMEOBIOTROP Bogor, wood waste of Meranti (Shorea leprosula), Cempedak (Arthocarpus integra), Mahagony (Swietenia macrophyla), and Durian (Durio zibetinus) were collected from small sawmill industry in Medan-North Sumatra, Indonesia. UF resin (UA-140) for binding was obtined from PT. Palmolite Adhesive Industry, Probolinggo-East Java, Indonesia.

\subsection{Methods}

\subsubsection{Material Preparation}

Sorghum bagasse was cut into $3 \mathrm{~cm}$ in length size. Wood shaving of Meranti, Cempedak, Mahagony and Durian wood were prepared by planer machine. All the particles namely wood shaving and shorghum bagasse were dried up to $4 \%$ moisture content

\subsubsection{Particleboard Manufacturing}

One layer particleboard was produced with the size of 25 $\mathrm{cm}$ by $25 \mathrm{~cm}$, thickness and density target were $1 \mathrm{~cm}$ and $0.70 \mathrm{gcm}^{-3}$ respectively. The mixture ratio of Sorghum bagasse and wood shaving in this research was 50/50 $(\% \mathrm{w} / \mathrm{w})$ refers to Guler et al. (2006). They reported that in $50 / 50$ mixture ratio able to improve of particleboard made from sunflower stalks and Calibrian pines mixture. Similar research was also showed by Iswanto (2014) reported that $50 / 50$ ratio of wood shaving and Jatropha fruit hulls resulting the improvement of bending properties. Furthermore, amount of $10 \%$ urea formaldehyde (UF) resin used for binding. Rotary drum blender was used for mixing particle and adhesive. After mat forming, mat was pressed using hot press machine at $130^{\circ} \mathrm{C}$ for 10 min and $30 \mathrm{kgcm}^{-2}$ pressure. Triplicate boards were prepared for each treatment. Total of boards were produced in this experiment amount of fifteen.

\subsubsection{Determination of Physical and Mechanical Properties}

Prior to physical and mechanical tests, specimens were conditioned for 7 days in a room temperature. The board parameters measured were air-dry density, moisture content (MC), water absorption (WA), thickness swelling (TS), modulus of rupture (MOR) and modulus of elasticity (MOE) in bending, and internal bond (IB). For all the sample size and evaluation of specimens refers to JIS A 5908-2003 (JSA 2003).

\subsubsection{Data Analysis}

Completely randomized design in three replicated for physical and mechanical properties. The treatment in this experiment namely Sorg (Sorghum bagasse as Control), Sorg/Mer (Sorghum bagasse and Meranti wood mixure), Sorg/Cem (Sorghum bagasse and Cempedak wood mixure), Sorg/Mah (Sorghum bagasse and Mahagony wood mixure),
Sorg/Dur (Sorghum bagasse and Durian wood mixure).

\section{Results and Discussions}

\subsection{Physical Properties}

The physical properties of particleboard that were evaluated such as density, moisture content (MC), water absorption (WA), and thickness swelling (TS).

\subsubsection{Density and Moisture Content}

The density and MC value of particleboard ranged between of 0.62 to $0.66 \mathrm{gcm}^{-3}$, and 4.66 to $5.48 \%$, respectively (Fig 1 and 2). The density results from this experiment was lower than the target of $0.70 \mathrm{gcm}^{-3}$. It was due to a spring back (reversible thickness). After conditioning process, board thickness exceeded the thickness target of $1.00 \mathrm{~cm}$. Furthermore, according to Bufalino et al. (2012), lower density due to loss particle during the manufacturing of particleboard. Kelly (1977) reported that several factors were influencing of board density such as wood species, hot pressing pressure, particles, adhesive and aditive quantity. Statistical analysis showed that all type of board in this experiment was not significantly affected the density parameters. Over all, the density of board had met standard. According to JIS A 5908-2003, the requirement of density value ranged between of 0.40 to $0.90 \mathrm{gcm}^{-3}$ (JSA 2003). The boards were classified into medium density particleboard (Maloney 1993).

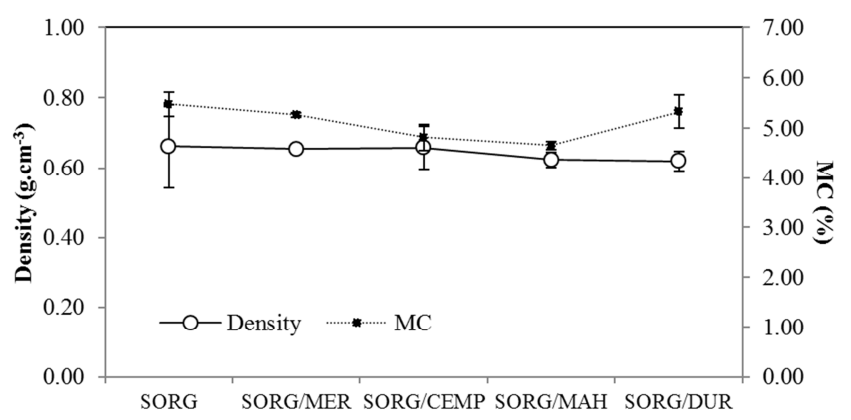

BOARD TYPES

Fig. 1. Effect of wood shaving mixture on board density and Moisture Content.

The lowest MC values were produced from sorghum bagasse and mahagony shavings mixture, then the highest $\mathrm{MC}$ value resulted from pure sorghum bagasse. According to the figure 2, over all the combination of sorghum bagasse with wood shaving had lower mositure content. This similar phenomenon was also showed by Garay et al. (2009) was reporting that wood had greater resistance of moisture so that will result the better stability in particleboard. Statistical analysis showed that the analysis of variance for boards type was significantly different to MC parameters. In generaly, almost all of the sample had fulfilled standard except of boards type made from sorghum bagasse combination with cempedak and mahagony wood shaving resulted below the standard. According to JIS A 5908-2003, 
the requirement of $\mathrm{MC}$ value ranged between of 5.00 to $9.00 \%$ (JSA 2003).

\subsubsection{Water Absorption and Thickness Swelling}

The WA and TS value of particleboard ranged between of 79.73 to $126.95 \%$, and 22.08 to $26.46 \%$, respectively (Fig 3 and 4). The lowest WA values were obtained by sorghum bagasse mixture with Cempedak wood shaving and then the highest value resulted from sorghum bagasse and Durian mixture. Furthermore, the lowest and highest TS values were obtained by sorghum bagasse mixture with Mahagony wood shaving and Durian, respectively.

Wood shaving had a significant effect on the WA and TS parameter. Gatchell et al. 1966; Clad 1967 cited in Bufalino et al. (2012) reported that high-density particleboard will result in higher contact between particles and improvement of their glue bonds which will reduce of TS. The similar trend was also in WA parameter. High contact particles will become physical barrier to water intake, and it will cause of decreasing the void among particles. Wood shaving and sorghum bagasse mixture resulted the lower TS value compared with pure sorghum bagasse particleboards. The increasing of wood per unit volume caused of increasing of resin efficiency to improve glue bonds, and the consequent will decrease of TS value. If compared with other wood type, Durian wood shaving treatment resulted the highest of TS value because the Durian wood has high specific gravity of 0.62 and also has medium shringkage classification (Krisdianto and Dewi, 2012). High density wood have greater swells and shrinks compared with low density wood to respond of moisture content change (Sellers et al. 1988 cited in Bufalino et al. 2012; Tsoumis 1991).

Hsu (1987) stated that WA and TS of board were determine by wood swelling itself, spring back effect, and furnish separation. Wood density is also another factors that influence of TS and WA value. Kelly (1977) High density of boards resulted high compression ratio, and it can absorb more water compared with low density at the equilibrium state. Similar statement was also stated by Febrianto et al (2010) stated that at the same board density target, a lower wood density will results high compression ratio of board and it caused of increasing the TS and WA value. Thickness swelling also described the strength of interparticle bond that is more pronounced as the internal bond (IB). Good compatibility among adhesive and particles will results strong particle bonding. The correlation of IB and TS showed that in Fig 5. Negative correlation was showed by TS and IB. The higher of IB value caused of decreasing of TS. It indicated that well bonding will be resulting better of dimensional stability.

Statistical analysis showed that all type of board in this experiment did not significantly affect to the TS parameters, but the contrary for WA parameters. Over all, the TS of board had not met JIS A 5908-2003 that requirement of maximum TS value of $12 \%$ (JSA 2003). It was due to sorghum bagasse was bulky materials. Kusumah et al (2016) reporrted that sorghum bagasse has bulk density amount of
$0.125 \mathrm{gcm}^{-3}$. Further more UF resin for binding in this research was another factors which also caused of the higher TS value.

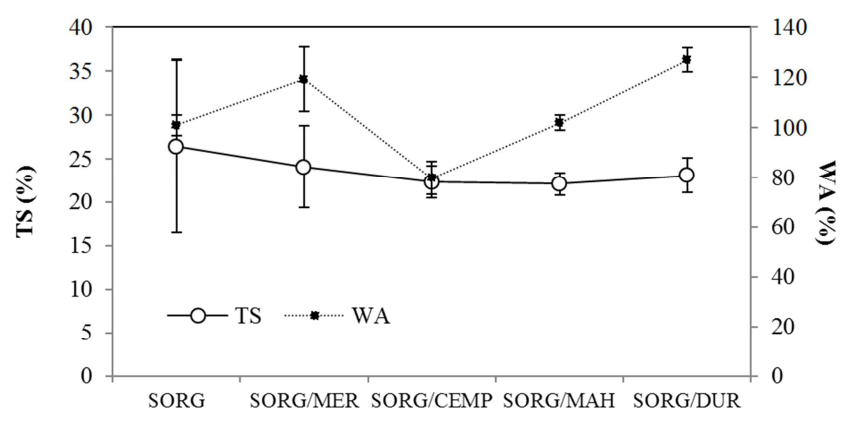

Board Types

Fig. 2. Effect of wood shaving mixture on thickness swelling and Water Absorption of board.

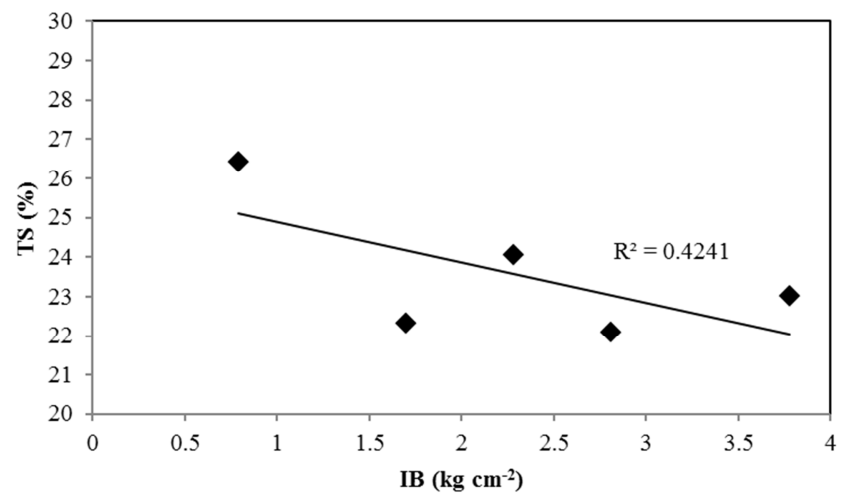

Fig. 3. Correlation of Internal Bond and Thickness swelling of particleboard.

\subsection{Mechanical Properties}

The average values of MOE, MOR, and IB ranged between of 10,140 to $16,353 \mathrm{kgcm}^{-2}, 73.21$ to $104.75 \mathrm{kgcm}^{-2}$, and 1.70 to $3.78 \mathrm{kgcm}^{-2}$, respectively (Fig 4 and 7). The lowest and the highest MOR values were resulted form sorghum bagasse mixed with Meranti and Cempedak wood shaving, respectively. The similar trend was also showed on MOE parameter. Over all, the present of wood shaving in manufacturing sorghum bagasse particleboard able to improve the bending strength. Sorghum bagasse is one of agricultural waste materials which had problem in bulky and lower strength properties. However, sorghum plant have short harvesting periods, similar chemical contents with wood (cellulose and lignin content). Thanapimmetha et al. (2011) reported that cellulose, hemicellulose and lignin content of sorghum stalk were $58.23 \%, 25.42 \%$ and $14.95 \%$, respectively. According to the fact, sorghum stalks have great potential to be developed as particleboard materials.

According to the Fig 4, wood shaving mixture showed that the low MOE value because the wood shaving used in this research was categorized into fine wood shaving. Maloney (1993) stated that fine wood shaving resulted the higher of IB, meanwhile for coarse wood shaving resulted the higher of 
bending. Homogenous particle size also affected the MOE value. The difference of size among sorghum bagasse and wood shaving as aone of factore which caused the low of MOE value.

Sorghum bagasse and Cempedak wood shaving mixture resulting of the best MOR value compared with other type of boards. It was predicted by Cempedak wood had lower density, so that resulted of higher compaction ratio at the same density target. Maloney (1993) stated that minimum 1.5 compression ratio will results better strength properties.

According to Fig 5, Density and MOR value had strong correlation. High density of board result in higher MOR value. Hiziroglu et al. (2005) also stated that board density was one of important factor affecting the physical and mechanical particleboard. Similar trend was also showed in MOE parameter (Fig 6). Several researchers reported that density had important role to affect of mechanical properties of board. The increasing of mechanical properties were resulted by increasing of board densities (Barboutis \& Philippou 2005; Zheng et al. 2006 cited in Bufalino et al. 2012). Kelly (1977) reported that the increasing of board density described of greater volume of wood particles which was compacted and the increasing of interparticle contact.

Over all, refers to JIS A 5908 (2003) the MOE of board did not fulfilled standard. While the MOR value had fulfilled standard excepted of mixture with Meranti wood shaving. This standard required of minimum MOE and MOR value of $20,400 \mathrm{kgcm}^{-2}$ and $82 \mathrm{kgcm}^{-2}$, respectively (JSA, 2003). Statistical analysis showed that all type of board in this experiment significantly affected the MOE parameters, however it did not significantly affected of MOR.

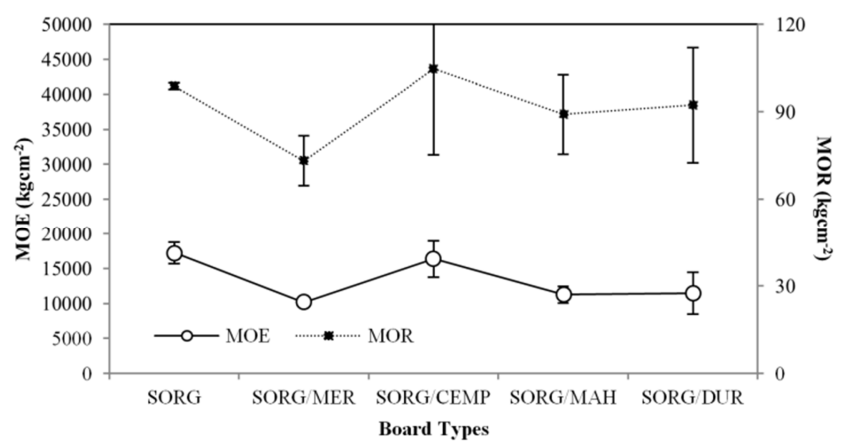

Fig. 4. Effect of wood shaving mixture on Modulus of elasticity and modulus of rupture of particleboard.

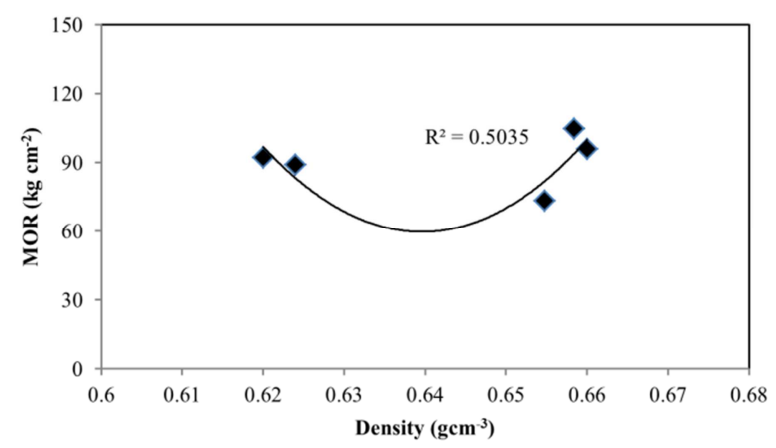

Fig. 5. Correlation of Density and MOR of particleboard.

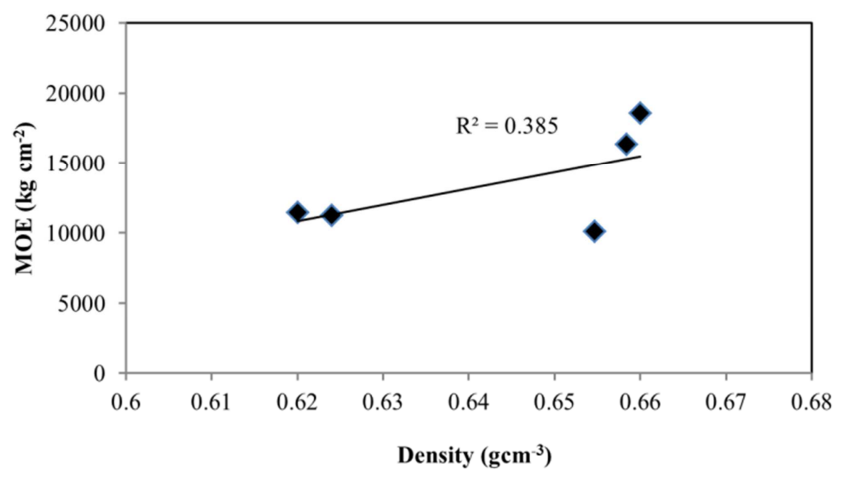

Fig. 6. Correlation of Density and MoE of particleboard.

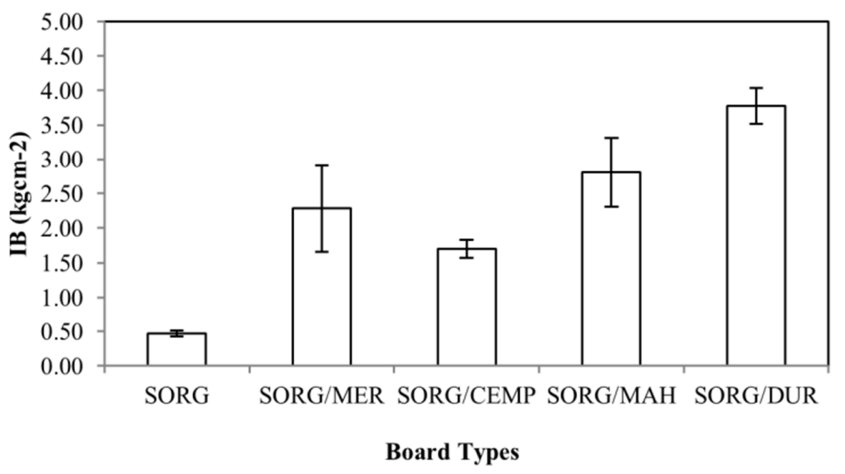

Fig. 7. Effect of wood shaving mixture on internal bond of particleboard.

In the previous research, Iswanto et al (2014) reported that the main problem in sorghum bagasse particleboard was the low of IB parameter. This problem had been solved in this experiment. According to the Fig 7, the present of wood shaving resulting of improvement IB value. Panels which was produced from sorghum bagasse and Durian wood shaving mixture resulted the highest IB values of $3.78 \mathrm{kgcm}^{-2}$. The utilization of fine wood shaving had been success to improve IB of board. This statement was stated by Maloney (1993). Cempedak shaving resulted the lower IB compared with other wood shaving, it was presumed by higher extractive content in cempedak wood. In the adhesion process, the extractives content caused of blocking of wood to absorb the adhesive, so that resulted bonding weakness between of wood and adhesive.

All the panels had met of JIS A 5908-2003 that requirement minimum IB of $1.50 \mathrm{kgcm}^{-2}$ (JSA 2003) excepted of pure sorghum bagasse particleboard. UF resin had better compatibility with acid materials. Pan et al. (2007) stated that acid condition particles more suitability with UF resin and resulted in good performance of bonding quality. Park et al. (2001) reported that $\mathrm{pH}$ and buffering capacity had strong influence on curing time and bonding strength of UF resin. Malanit et al. (2009) reported that UF resin curing time and bonding strength will increase or decrease respectively depend on $\mathrm{pH}$ and buffering capacity of particle. Over all materials (wood and sorghum bagasse) which used in this research have acid condition, for example Mahagony wood and sorghum bagasse $\mathrm{pH}$ were 4.88 and 6.98 respectively (Iswanto et al 2011; Iswanto 2014). Fengel and Wegener (1984) stated that subtopic and tropical woods have average 
$\mathrm{pH}$ between of 3.30-6.40 and 3.70- 8.20, respectively. Statistical analysis showed that all type of board in this experiment do not significantly affected the IB parameters

\section{Conclusion}

Wood shaving and sorghum bagasse mixture resulted improvement of board thickness swelling value. Combination of Cempedak and Mahagony wood resulted of the lower thickness swelling value. The bending properties, Cempedak wood shaving resulted of better improvement of bending properties except of the MOE parameter had not met of JIS A 5908 (2003). The present of wood shaving caused of increasing the internal bond (IB) parameter. All the treatments resulted of IB value which had met of JIS A 5908 (2003).

\section{Acknowledgment}

We would like to express my sincerely thanks to Directorate General Higher Education Ministry of Education and Cultural Republik Indonesia for funding support by Competitive Research Grant (Hibah Bersaing-No: 16/UN.2.3.1/KEU/SP/2014). My sincere appreciation also goes to SEAMEO-BIOTROP Bogor for Sorghum bagasse materials support.

\section{References}

[1] Iswanto AH, Azhar I, Supriyanto, Susilowati A. 2014. Effect of resin type, pressing temperature and time on particleboard properties made from sorghum bagasse. Agriculture, Forestry and Fisheries 3 (2): 62-66. doi: 10.11648/j.aff.20140302.12.

[2] Iswanto AH, Febrianto F, Hadi YS, Ruhendi S, Hermawan D. 2012. Physical and Mechanical Properties of Particleboard Made from Jatropha (Jatropha curcas) Fruit Hulls Reinforced with Wood Particle. J. Ilmu dan Teknologi Kayu Tropis Vol. 10 (2): 103-111.

[3] Subiyanto B, Rasyid E, Gopar M, Firmanti A. 2008. Veneer and thin plywood overlaid for quality improvement of particleboard made of palm oil empty fruit bunches (EFB). $J$. Trop. Wood Sci. Tech. 6 (1): 17-20.

[4] Norvydas V, Minelga D. 2006. Strength and stiffness properties of furniture panels covered with different coatings. Materials Sci 12 (4): 328-332.

[5] Iswanto AH. 2014. Characterization of Jatropha curcas L Fruit Hulls and Its Utilization to Produce High Quality Particle Board. Dissertation. Institut Pertanian Bogor. Indonesia: Bogor.

[6] Bektas I, Guler C, Kalaycioglu H, Mengeloglu F, Nacar M. 2005. The Manufacture of Particleboards using Sunflower Stalks (Helianthus annuus 1.) and Poplar Wood (Populus alba L.). J. Composite Materials: 39 (5): 467-473.

[7] Russell C, Moody, Hernandez R, Liu JY. 1999. Glued Structural Members. In Chapter 11: Wood Handbook-Wood as an Engineering Material. FPL-USDA Forest Service, Madison, Wisconsin, USA.
[8] Guler C, Bektas I, Kalaycioglu H. 2006. The experimental particleboard manufacture from sunflower stalks (Helianthus annuus L.) and Calabrian pine (Pinus brutia Ten.). For. Prod. $J 56$ (4): 56-60.

[9] [JSA] Japanese Standard Association. 2003. Japanesse Industrial Standard Particle Board JIS A 5908. Tokyo: Japanese Standard Association.

[10] Bufalino L, Albino VCS, VA de Sá, Corrêa AAR, Mendes LM, Almeida NA. 2012. Particleboards Made from Australian Red Cedar: Processing Variables and Evaluation of MixedSpecies. J. Tropical Forest Science 24 (2): 162-172.

[11] Kelly MW. 1977. Critical Literature Review of Relationship Between Processing Parameter and Physical Properties of Particleboard. General Technical Report FPL-10. Wisconsin: Department of Agriculture Forest.

[12] Maloney TM. 1993. Modern Particleboard and Dry-Process Fiberboard Manufacturing (Updated Edition). San Francisco: Miller Freeman.

[13] Garay RM, MacDonald F, Acevedo ML, Calderón B, Araya JE. 2009. Particleboard Made with Crop Residues Mixed with Wood from Pinus radiata. J. BioResources: 4 (4): 1396-1408.

[14] Krisdianto, Dewi LM. 2012. Jenis Kayu Untuk Mebel. PUSLITBANG Keteknikan Hutan dan Pengolahan Hasil Hutan, Badan Penelitian dan Pengembangan Kehutanan, Kementerian Kehutanan, Bogor.

[15] Tsoumis, G. 1991. Science and Technology of Wood: Structure, Properties, Utilization. New York (US): Van Nostrand ReinholdPr.

[16] Hsu, W. E. 1987. A Process for Stabilizing Waferboard/OSB. Proceedings of the 21st International Particleboard Symposium, (IPS'87), Washington State University, Pullman, pp: $219-236$.

[17] Febrianto F, Hidayat W, Samosir TP, Lin HC, Soong HD. 2010. Effect of Strand Combination on Dimensional Stability and Mechanical Properties of Oriented strand Board Made from Tropical Fast Growing Tree Species. J. Biological Science 10 (3): 262-272.

[18] Kusumah SS, Umemuraa K, Yoshiokac K, Miyafujic H, Kanayama K. 2016. Utilization of sweet sorghum bagasse and citric acid formanufacturing of particleboard I: Effects of predrying treatment andcitric acid content on the board properties. J. Industrial Crops and Products 84: 34-42.

[19] Thanapimmetha A, Vuttibunchon K, Saisriyoot M, Srinophakun P. 2011. Chemical and Microbial Hydrolysis of Sweet Sorghum Bagasse for Ethanol Production. Proceeding in World Renewable Energy Congress 2011 at Sweden 8-13 May 2011, Linkoping, Sweden.

[20] Hiziroglu, S., Jarusombuti, S. and Fuengvivat, V. 2005. Surface Characteristics of Wood Composites Manufactured in Thailand. Build. Environ., 39: 1359-64.

[21] Pan, Z., Zheng Y, Zhang R, Jenkins B. M. 2007. Physical Properties of Thin Particleboard Made from Saline Eucalyptus. J. Industrial Crops and products 26: 185-194.

[22] Park BD, Kim Y, Rield B. 2001. Effect of wood-fiber characteristics on medium density fiberboard (MDF) performance. J. Korean Wood Sci. Tech. 29: 27-35. 
[23] Malanit P, Barbu MC, Fruhwald A. 2009. The Gluability and Bonding Quality of an Asian Bamboo (Dendrocalamus asper) for the Production of Composite Lumber. J. Tropical Forest Science: 21 (4): 361-368.

[24] Iswanto AH, Sucipto T, Febrianto F. 2011. Acidity and
Buffering Capacity of Some Tropical Wood. J. Ilmu dan Teknologi Hasil Hutan 4 (1): 21-24.

[25] Fengel D and Wegener G. 1984. Wood-Chemistry, Ultrastructure, Reactions. Walter de Gruyter, Berlin and New York. 